\title{
GCU
}

Glasgow Caledonian

University

University for the Common Good

\section{Getting into it in the wrong way: interpretative phenomenological analysis and the} hermeneutic circle

Gyollai, Daniel

Published in:

Nursing Philosophy

DOI:

10.1111/nup.12294

Publication date:

2020

Document Version

Author accepted manuscript

Link to publication in ResearchOnline

Citation for published version (Harvard):

Gyollai, D 2020, 'Getting into it in the wrong way: interpretative phenomenological analysis and the hermeneutic circle', Nursing Philosophy, vol. 21, no. 2, e12294. https://doi.org/10.1111/nup.12294

\section{General rights}

Copyright and moral rights for the publications made accessible in the public portal are retained by the authors and/or other copyright owners and it is a condition of accessing publications that users recognise and abide by the legal requirements associated with these rights.

Take down policy

If you believe that this document breaches copyright please view our takedown policy at https://edshare.gcu.ac.uk/id/eprint/5179 for details of how to contact us. 
Getting into It in the Wrong Way: Interpretative Phenomenological Analysis and the Hermeneutic Circle

\begin{abstract}
This article critically analyses the hermeneutic commitment of Interpretative Phenomenological Analysis (IPA). In the theoretical framework of IPA, the role of preconceptions and prejudices is consistently downplayed; priority is given to the participant's own words. Paley has argued that IPA's interpretative phase is always and necessarily determined by the researcher's fore-conceptions, as opposed to the participant's narrative. I demonstrate that IPA's failure to recognise the importance of an external frame of reference in interpretation may arise from the misunderstanding of the method's hermeneutic underpinnings. I essentially argue that bracketing the researcher's fore-conceptions during the initial phases of IPA is merely an illusion. While it is beyond the scope of this article to dispute whether IPA is genuinely phenomenological, my claim ultimately poses a challenge to IPA's phenomenological commitment on its own terms. The article concludes with a proposal to substantially improve IPA's consistency with hermeneutic tradition and its grounding in phenomenological philosophy.
\end{abstract}

\title{
Keywords
}

Interpretative Phenomenological Analysis, Heidegger, Gadamer, bracketing, hermeneutic circle, fusion of horizons

\section{Introduction}

Interpretative Phenomenological Analysis (IPA) is a qualitative research method designed to analyse how individuals make sense of lived experiences, such as major transitions in their life or illness experiences. IPA has been developed by Jonathan Smith and most comprehensively set out by Smith et al. (2009). The purpose of the method is to provide detailed analytical account of lived experiences in the participants' own terms, rather than to conduct an analysis guided by a predefined category system relying on the preconceptions and theoretical prejudices of the researcher. According to Smith et al. (2009, p. 32) this criterion makes IPA a phenomenological research method. IPA further has a hermeneutic commitment as the authors adhere to the view according to which every phenomenological inquiry requires interpretation.

Although claimed to be phenomenological, IPA is predominantly centred in psychology. Giorgi (2010) argues that instead of 'Phenomenological', the method should be termed 'Interpretive Experiential Analysis' due to its questionable affiliation to phenomenological philosophy. Both van Manen (2017) and Zahavi (2019b, pp. 126127) have pointed out that although IPA is clearly qualitative, studying lived experiences is not equivalent with being phenomenological. Moreover, Zahavi (2019b, pp. 126-128, 2019c) argues that it is not entirely clear how the method draws upon phenomenological philosophy: on the one hand, IPA fails to operationalise concepts of phenomenological philosophy that would be instrumental for its very purpose, and misinterprets others it actually draws from, on the other. IPA's understanding of bracketing, indeed, shows little resemblance to the Husserlian concept of epoché (or bracketing), one of the central elements of Husserl's phenomenological method. Epoché means the suspension of the natural attitude, i.e. the dogmatic belief in the absolute, 'mind-independent' existence of the world. As Zahavi notes, epoché does not imply careful examination of worldly objects, free from prejudices and theoretical preconceptions, in order to let the objects show themselves as what they are (Zahavi, 2019b pp. 33-34). Epoché provides an opportunity to pay attention to how and why worldly objects show themselves as they do. This is when we start realising our own constitutive role in the way in which the objects are revealed and with the meaning they have; which ultimately enables the philosophical analysis of the correlative relationship between ourselves and the world, between subjectivity and objectivity (Zahavi, 2019a, 2019b, pp. 32-38, 2019c). Conversely, to IPA, bracketing means a certain interviewing and transcript analysis technique, where researchers access the meaning of the participant's narrative by temporarily suppressing and silencing their own preconceptions on the matter. However, the objective of this article is not to dispute whether IPA's bracketing technique is phenomenological or not, but to problematise the technique's hermeneutic structure. Paley (2017, Ch. 5-6) has argued that IPA's interpretative phase, as opposed to Smith et al.'s claim (2009, p. 90), never arises from the participant's own words, but is always and necessarily based on the researcher's perspective imported 
from the outside. In other words, IPA's major methodological innovation in empirical research, the bracketing of the researcher's preconceptions during the early stages of the analysis is merely an illusion. Following a brief conceptual overview of IPA's hermeneutic underpinnings, I will demonstrate that the failure to recognise the importance of preconceptions may lie in the misinterpretation of the Heideggerian and Gadamerian concepts of interpretation. This claim, nonetheless, subsequently poses a challenge to IPA's phenomenological commitment on its own terms. In the final section of the article, I propose some modifications to IPA to resolve this issue and substantially improve the method's grounding in phenomenological philosophy.

\section{IPA and hermeneutics}

IPA's hermeneutic focus draws predominantly, although not exclusively, from Martin Heidegger and Hans-Georg Gadamer; it does so rather selectively nonetheless. In the theoretical framework of IPA, the role of preconceptions and prejudices is consistently downplayed. Fore-conceptions and fore-understandings are portrayed as obstacles in the process of interpretation that should better be bracketed off in order to come to a genuine understanding of the participants' own meaning. In the Heideggerian and Gadamerian concepts of interpretation, nevertheless, the opposite is true.

\section{Martin Heidegger}

Heidegger argues that 'every interpretation which is to contribute some understanding must already have understood what is to be interpreted' (2010, p. 147). Fore-understandings are the precondition of interpretation. This follows precisely from Heidegger's approach to understanding. Heidegger maintains that separation of object and subject is misleading as we can only understand both the self and the world in their interconnectedness:

Self and world belong together in the single entity, the Dasein. Self and world are not two beings, like subject and object, or like I and thou, but self and world are the basic determination of the Dasein itself in the unity of the structure of being-in-theworld. (Heidegger, 1988, p. 297)

Heidegger further argues that we are dependent upon one another, and being-in-the-world means being-with-oneanother (Heidegger, 1988, pp. 178, 297-98; 1985, pp. 236-250); 'being-with remains existentially constitutive for being-in-the-world' (Heidegger, 2010, p. 118). The self, the world and others within form an inseparable unit. Pure reasoning in isolation is, therefore, not possible, we can only think about the objects of the world from within the world and in relation to others; embeddedness and intersubjectivity are the default characteristic of our experiences and consciousness (Moran, 2000, p. 160; Watts, 2011, pp. 22, 51). Moreover, given the temporality of Dasein (human existence), understanding is necessarily determined by a particular historical context, the cultural heritage of our time (Heidegger, 1988, pp. 22, 169; 2010, pp. 19-20, 369-376; Watts, 2011, pp. 135-137). Our initial understanding of the world is second-hand experience; the society we live in, the public world provides a ready-made interpretation of things. We are born and socialise into a particular zeitgeist; we are thrown into the world (Heidegger, 2010, pp. 131, 169-174). We inherit the knowledge, beliefs and general understanding of the world of a given period of time.

What is important is that, due to this historical embeddedness of Dasein, we always have an inherited, 'primordial' understanding of the world and its entities that helps us to make sense of worldly objects (Watts, 2011, pp. 4345). To demonstrate this, Heidegger points out that 'we never hear noises or complexes of sound but the creaking wagon, the motorcycle ... the woodpecker tapping, the cracking fire'. Heidegger calls this 'hearkening', a hearing that understands, and he notes: 'it requires a very artificial and complicated attitude in order to hear a pure noise' (Heidegger, 2010, p. 158). Similarly, we do not only see a pair of tires and a tube structure when we look at a bicycle, but we instantly know we are looking at a bicycle. In fact, perceiving the rounded shape pair of things as tires would already imply a familiarity with the concept of tire. Heidegger argues that we always and instantly perceive things we encounter as something that has a function, and interpret them in the context of and through the way in which they relate to other entities we already know (Heidegger, 1988, pp. 292-294; van Manen, 2016, pp. 107-110). 'Things at hand are always already understood in terms of a totality of relevance' (Heidegger, 2010, p. 145). Whenever we look at an object, what first appears to us is its possible purpose: the cupboard as something to store my mugs; the mug as something to pour my coffee into; the coffee as something to wake me up, and so 
on. The functionality, i.e. the possible relatedness of things to other entities is automatically and unconsciously disclosed by our pre-existing knowledge of the world. The same applies to the interpretation of statements, assertions or judgements in communication (Heidegger, 2010, p. 149). Heidegger refers to this network of preexisting knowledge as fore-havings, fore-sights and fore-conceptions: fore-having as the overall, already known context in which the thing to be interpreted is involved; fore-sight as our particular approach to or take on the matter; and fore-conception as a provisional (or definite) significance or meaning attached to the thing as conceived and disclosed in interpretation. The three together constitute the fore-structure of understanding. All our perceptions and encounters of things in our environment are grounded in the fore-structure (Heidegger, 2010, pp. 144-149; Watts, 2011, pp. 64-68). Watts specifically exemplifies the concept of fore-having with reference to psychologists whose fore-having would be their general understanding of human nature (Watts, 2011, p. 68). Whenever psychologists analyse a new, yet unknown feature of consciousness, they naturally interpret it against the background of what they already know about consciousness.

Heidegger argues that things not always show themselves as what they are, but in a 'self-concealing' manner (Moran, 2000, p. 229). Phenomena can be 'covered up', and interpretation is, therefore, inevitable: 'explication of phenomena must be opposed to the naïveté of an accidental, immediate and unreflective beholding' (Heidegger, 2010, p. 34). Interpretation is the process that makes the relevance of the yet uncovered ('veiled') aspects of things explicit by appropriating what has already been understood based on our fore-structure. 'Interpretation is never a presuppositionless grasping of something previously given’ (Heidegger, 2010, p. 146). Meaning emerges once we come to understand the purpose of something as something, and it becomes intelligible in terms of its functional interconnectedness with other entities in our world (Watts, 2011, p. 68; Heidegger, 2010, pp. 146-147). Thus, Heidegger argues that understanding is always and inescapably a circular process that nurtures itself from our fore-conceptions of phenomena; every new experience and knowledge is grounded in the fore-structure.

While IPA acknowledges this central role of fore-conceptions in the process of interpretation, Smith et al. urge to 'look closely' at what Heidegger says, and the authors quote the following passage from Being and Time:

Our first, last, and constant task in interpreting is never to allow our ... fore-conception to be presented to us by fancies and popular conceptions, but rather to make the scientific theme secure by working out the fore-structures in terms of the things themselves. (Heidegger, cited in Smith et al., 2009, p. 25) ${ }^{1}$

Smith et al. conclude that fore-conceptions seem to pose a certain 'danger' and present 'obstacle' to interpretation; 'priority should be given to the new object, rather than to one's preconceptions' (Smith et al., 2009, p. 25). Partly based on this reading of Heidegger, IPA follows a methodology where researchers are advised to avoid interpretation at the early stages of the analysis by bracketing their fore-conceptions, and to take the descriptive stance of a naïve listener. Heidegger, indeed, maintains that the task of phenomenology is 'to let that what shows itself be seen from itself, just as it shows itself from itself' (Heidegger, 2010, p. 32). However, the way in which things show themselves is precisely the way in which things are described from one's perspective grounded in the fore-structure: for Heidegger, description is interpretation (Finlay, 2009; Dybel, 2004). First of all, in the passage cited by Smith et al., Heidegger does not prescribe a formula for interpretation ('development of understanding') as a method to be followed e.g. in textual interpretation. Rather, he explicates interpretation with an ontological significance as nothing less than the universal functioning of human understanding. Thus, it is perhaps worth taking an even closer look at what Heidegger says just a few lines above the earlier passage cited by Smith et al.:

But to see a vitiosum in this circle and to look for ways to avoid it, even to feel that it is an inevitable imperfection, is to misunderstand understanding from the ground up (...) What is decisive is not to get out of the circle, but to get into it in the right way. The circle of understanding is not a circle in which any random kind of knowledge operates, but it is rather the expression of the existential fore-structure of Dasein itself. The circle must not be degraded to a vitiosum, not even to a tolerated one. A positive possibility of the most primordial knowledge is hidden in it. (Heidegger, 2010, p. 148)

Secondly, and more significantly, Smith et al.'s interpretation of the passage is misleading. It does not suggest that (hypothetically) we should interpret the things 'in themselves' and by silencing our fore-understanding (Wachterhauser, 1986, pp. 20-28). Rather, Heidegger means the development, reconfiguration or restructuring of 
our fore-understanding in a way in which it most intelligibly discloses and mirrors the significance and relevance of the thing in their interconnectedness. How would we know whether we encountered something genuinely new, if we approached the thing by bracketing our fore-understanding? Only by analysing every aspect of something that shows itself from a particular perspective we can safely declare that it cannot be fully interpreted as something we have previously known. But then, if so, nor could we genuinely describe it, we should have to find a name for it first.

The authors refer to the concept of hermeneutic circle throughout the text without getting into it in the right way. The hermeneutic circle always starts with Heidegger's as-structure. Understanding emerges in interpretation once something becomes intelligible as something previously known. IPA fails to recognise that the circle necessarily starts with one's own fore-conceptions; it would merely be a hermeneutic vacuum otherwise. The words of the text only gain meaning in relation to something; without fore-conceptions there is no interpretation, without interpretation there is no new insight. Gadamer makes this even more explicit in Truth and Method.

\section{Hans-Georg Gadamer}

Gadamer, influenced by Heidegger, has extensively analysed the process of understanding and how meaning is constituted during interpretation. In agreement with Heidegger, Gadamer argues that interpretation necessarily relies on our fore-conceptions; we cannot 'extinct' our own self when listening to someone or reading a text. What is crucial according to Gadamer is to stay aware of our own biases, to foreground them and to constantly question the validity of our fore-understanding in relation to the new content. This awareness does not mean that we should completely ignore and shut our preconceptions out; what is needed is sensitivity 'to the text's alterity' (Gadamer, 2004, pp. 268-273). For Gadamer, understanding is always dialogical: we come to understand the world in conversation with others. He explored the ways in which we rely on our inherited fore-knowledge and worldview, and simultaneously open up for different interpretations by others, which he called the fusion of horizons (Moran, 2000, pp. 248-252). Husserl referred to horizon as all the possible aspects and features of an object that can be perceived from a particular perspective at a given time (Moran, 2000, pp. 161-163). Gadamer applied the concept of horizon to the thinking mind: 'a person who has a horizon knows the relative significance of everything within this horizon' (Gadamer, 2004, p. 301). Horizon in Gadamerian sense is perhaps best described as one's view and general understanding of phenomena and their context at a given time, the totality of possibly relevant foreconceptions. To understand one another and to come to a common understanding during conversation, we transpose ourselves into the other person. 'Understanding is always the fusion of these horizons' (Gadamer, 2004, p. 305). Every interpretation is changing of views, and neither the imposition nor the abandonment of our own over what has to be interpreted. In conversation we bring our preconceptions, opinions 'into play' and put them 'at risk' (Gadamer, 2004, pp. 298-299, 398). Gadamer notes that the 'common dictum' is neither mine, nor my partner's, it is always something new: 'old and new are always combining into something of living value, without either being explicitly foregrounded from the other' (Gadamer, 2004, pp. 388, 305). To introduce the Gadamerian concept of interpretation, Smith et al. cite the following passage from Truth and Method:

It is necessary to keep one's gazes fixed on the things throughout all the constant distractions that originate in the interpreter himself. A person who is trying to understand a text is always projecting. He projects a meaning for the text as a whole as soon as some initial meaning emerges in the text ... Working out this fore-projection, which is constantly revised in terms of what emerges as he penetrates into the meaning, is understanding what is there. (Gadamer, cited in Smith et al., 2009, p. 26)

Unfortunately, the ellipsis in the middle of the citation indicates the omission of a sentence that is at the heart of both Gadamer's reasoning and the argument of this article: 'Again, the initial meaning emerges only because he is reading the text with particular expectations in regard to a certain meaning' (Gadamer, 2004, p. 269). According to the authors' interpretation of the passage, 'one may only really get to know what the preconceptions are once the interpretation is underway' (Smith et al., 2009, p. 26). Smith (2007) argues that understanding may actually work from the text to the fore-structure. Interpretation is, as has been discussed, an automatic and unconscious process. As the object of interpretation, it is, necessarily, the text that triggers and activates our fore-conceptions, yet understanding works the other way around. No one can learn and, all of a sudden, understand the English language by simply gazing at the front page of the Guardian. With the next citation the authors' aim is to demonstrate why the text itself influences interpretation: 
Every revision of the fore-projection is capable of projecting before itself a new projection of meaning; rival projects can emerge side by side until it becomes clearer what the unity of meaning is; interpretation begins with fore-conceptions that are replaced by more suitable ones. This constant process of new projection constitutes the movement of understanding and interpretation. (Gadamer, cited in Smith et al., 2009, p. 26)

Our horizon, our filter is constantly changing and upgrading during interpretation; ideas pop up and go. When we are reading a text, the interpretation of the parts we have already read impacts upon the interpretation of forthcoming ones. Not only that, the initial bits might as well gain different meaning following the interpretation of the text as a whole. Certain parts, initially obscure, gain meaning through the interpretation of others, and ultimately, of the whole, and vice versa. What is decisive is that the very first point of departure that determines the initial direction of the entire interpretative process is always grounded in our fore-understanding and not in the text itself. Based on the next citation the authors draw the conclusion that preconceptions can 'hinder' interpretation (Smith et al., 2009, p. 26).

A person trying to understand something will not resign himself from the start to relying on his own accidental fore-meanings, ignoring as consistently and stubbornly as possible the actual meaning of the text until the latter becomes so persistently audible that it breaks through what the interpreter imagines it to be. Rather a person trying to understand a text is prepared for it to tell him something ... But this kind of sensitivity involves neither neutrality with respect to content nor the extinction of one's self, but the foregrounding and appropriation of one's own fore-meanings and prejudices. The important thing is to be aware of one's own bias, so that the text can present itself in all its otherness and thus assert its own truth against one's own foremeanings. (Gadamer, cited in Smith et al., 2009, p. 26)

Gadamer by no means censures or proposes to disregard our preconceptions, on the contrary, to foreground and appropriate them. IPA, however, opts for the former. Gadamer specifically notes that interpretation inescapably involves prejudices, but 'it is neither possible, necessary, nor desirable that we put ourselves within brackets' (Gadamer, 1979, p. 152). Moreover, he argues:

To try to escape from one's own concepts in interpretation is not only impossible, but manifestly absurd. To interpret means precisely to bring one's own preconceptions into play so that the text's meaning can really be made to speak for us. (Gadamer, 2004, p. 398)

Gadamer's concept of prejudice is analogous to Heidegger's fore-structure, with no negative connotation attached. Prejudices are pre-judgements, fore-conceptions that are a function of history and tradition, therefore ineliminable (Moran, 2000, p. 278). Our understanding is inescapably influenced by our past; Gadamer refers to this as history of effect (Gadamer, 2004, p. 299). Although often operate unconsciously, prejudices 'constitute the initial directedness of our whole ability to experience. Prejudices are biases of our openness to the world. They are simply conditions ... whereby what we encounter says something to us' (Gadamer, 1977, p. 9). We get 'struck' by and start paying attention to the text alterity only when we encounter inconsistency, i.e. when our hidden prejudices fail us and become questionable (Gadamer, 2004, p. 294). Thus 'provoked' by the text we are put in a position to identify a so far unnoticed prejudice and denounce it as such, whereby it becomes 'authentically' ours, part of our explicit interpretative toolkit (Gadamer, 1979, pp. 157-158). We now also have the opportunity to suspend its validity and foreground it, which neither means silencing, nor casting it aside, but considering it in contrast to the new opinion: 'only by being given full play is it able to experience the other's claim to truth and make it possible for him to have full play himself' (Gadamer, 2004, pp. 298-299). Thus, Smith is right by suggesting there are prejudices we are not aware of and have no control over, and which we may better understand by engaging with the text (Smith et al., 2009, pp. 25-27; Smith, 2007). But, then, how are we to silence them before they take effect, and more importantly, for what purpose? Precisely by hidden prejudices being provoked, confronted, hence revealed we start questioning and understanding ourselves in relation to phenomena, and simultaneously opening up to yet unrecognised aspects of the world. Prejudices are all we have, really, which we constantly revalidate and reconfigure over time. This is why Gadamer maintains: 'It is not so much our judgements as it is our prejudices that constitute our being' (Gadamer, 1977, p. 9).

It is irrelevant whether a prejudice is correct or incorrect, but the relevant question is whether it is methodologically justified (Gadamer, 2004, pp. 272-273). The value of prejudices is always derivative as well as 
provisional, their credentials are subject to future challenge. It is 'temporal distance' that helps to rule out arbitrary prejudices that do not become confirmed during the 'passage of time'. Furthermore, there is a dialectic relationship between the 'old' fore-conception and the 'new' that replaces it. The 'new' will always need the 'old' to know by what and in what it is opposed or superimposed (Gadamer, 2004, p. 298; 1978, pp. 156-158). For this very reason, IPA researchers would not be able to test the validity of the theoretical interpretation attached to their findings without embedding it in a conceptual framework.

\section{Phases of IPA and hermeneutic shortcomings}

\section{Parking 'hobby horses' - data collection}

The most recommended data collection method to conduct IPA is in-depth interview. The interviewees should have the opportunity to provide a rich and detailed first-person account of their experiences, stories and concerns. According to the guidance, during the interview phase of the project:

You are leaving your research world and coming round the hermeneutic circle to the participant's world ... By focusing on attending closely to your participant's words, you are more likely to park or bracket your own pre-existing concerns, hunches and theoretical hobby horses. It is not that you should not be curious and questioning; it is that your questioning at this phase of the project should all be generated by attentive listening to what your participant has to say. (Smith et al., 2009, p. 64)

First, disregarding our fore-havings would be very complicated, as listening to someone, making sense of one's words inevitably triggers the activation of our fore-understandings of what we are listening to. In hermeneutic terms, to answer the question 'What do they mean by this?' we are trying to create an intelligible sequence of what we just heard by appropriating, and against the background of, our fore-knowledge. No matter how experienced they are, psychologists are not psychics; trying to understand implies interpretation, and interpretation is the appropriation of fore-conceptions. Second, as has been argued, understanding is always a fusion of horizons, ours and our partner's horizon, it is never the abandonment of our own. We never leave our world in interpreting someone, on the contrary we try to 'transpose' ourselves into the situation. Gadamer underlines that the emphasis in the process of 'transposing ourselves' is precisely on ourselves:

If we put ourselves in someone else's shoes, for example, then we will understand him - i.e. become aware of the otherness, the indissoluble individuality of the other person - by putting ourselves in his position. (Gadamer, 2004, p. 304)

We surely disregard ourselves in the sense that we do not expect others to interpret certain experiences as we do, but their unique interpretation is precisely unique in relation and in comparison to ours. Moreover, our research world, our experiences and professional knowledge are all constitutive of our otherness, i.e. our horizon. Even if we do not explicitly activate and operationalise a specific experience or concept relating to the topic when interpreting our partner, they are still irreversibly and inseparably part of our whole being; our cognitive and interpretative capacity, the filter through which we are trying to understand our partner.

Smith et al. argue that 'it can sometimes be useful' to collect extra data after the interview, such as participant observation to understand the local context and activities, all of which are helpful to conceptualise the interview and develop the analysis (Smith et al., 2009, p. 73). In other words, the authors essentially advise the researcher to gain some fore-understandings in relation to the interviewee in order to facilitate the subsequent interpretation process. It is not entirely clear why this is not an authoritative prescription and to be conducted prior to the interview; failing to collect such data would probably alter the outcome of the interpretation.

\section{Reducing the 'noise' - reading, noting, descriptive comments}

IPA's initial phase should be 'descriptive' with an 'exploratory' focus 'close to the participant's explicit meaning' rather than being interpretative (Smith et al., 2009, pp. 82-88). This section will demonstrate why IPA is inescapably interpretative from the outset. According to the authors, in the first phase of the analysis, the researcher should 'read and re-read' the transcript which involves the 'recording' of our: 
Most striking observations about the transcript in a notebook, in order to help you to bracket them off for a while. Sometimes the process of beginning analysis is accompanied by a feeling of being overwhelmed by ideas and possible connections - it can help to reduce the level of this noise by recording it somewhere, thus allowing your focus to remain with the data. You can always come back to these notes later, safe in the knowledge that your first impressions have been captured. (Smith et al., 2009, p. 82)

Conversely, the researcher is simultaneously asked to make 'exploratory notes' of 'anything of interest within the transcript', and 'produce a comprehensive and detailed set of notes and comments on the data' (Smith et al., 2009, p. 83).

Interesting in terms of what? Comprehensive as to what kind of aspect? Nothing is interesting in itself. Interesting always means interesting in terms of something. The authors help by adding that interesting here means interesting in terms of whether something helps 'to identify specific ways by which the participant talks about, understands and thinks about an issue' (Smith et al., 2009, p. 83); i.e. interesting in terms of the respective research question. To decide whether something the participant says is interesting in these terms, the researcher must understand what specific ways of understanding an issue means. To put it simply, we have to know what we are searching for. As Gadamer notes: 'We can understand the text only when we have understood the question to which it is an answer' (Gadamer, 2004, p. 363). Since the aim is to identify and reveal interesting bits about the specific ways by which the participant understands an issue, the researcher must have a fore-understanding of what the ways of understanding an issue are in general. We would not be able to find something interesting in the transcript in terms of how the participant understands an issue if we did not already have a concept of understanding. Whenever we formulate a research- or interview question, we must always already have a grasp of the subject matter. In the very first pages of Being and Time (see also Moran, 2000, p. 236), Heidegger explains the hermeneutic structure of a question:

Every questioning is a seeking. Every seeking takes its lead beforehand from what it sought. Questioning is a knowing search for beings in their thatness and whatness. The knowing search can become an investigation, as the revealing determination of what the question aims at ... As a seeking, questioning needs prior guidance from what it seeks. The meaning of being must therefore already be available to us in a certain way. We intimated that we are always already involved in an understanding of being ... This average and vague understanding of being is a fact. (Heidegger, 2010, p. 4)

Thus, when we are reading the transcript, we are trying to find interesting bits, comments that refer to, and might be relevant as to how the participant understands an issue in relation to our general, 'vague' understanding of the concept of understanding. The 'noises' we hear while reading the transcript and our 'striking observations' the authors suggest to bracket are precisely the manifestations of our revelation and identification of something as interesting the participant said in terms of our own concepts of understanding in general. These are the cognitive alerts of when something the participant says becomes intelligible in terms of our understanding of understanding. The question arises: how could we find something interesting in the transcript if we tried to ignore and shut out our own concepts only in terms of which something, anything can be interesting? What is essentially asked from the researcher at this stage is to try not to interpret the text, but meanwhile to find its interesting bits. With the bicycle example: on the one hand, the researcher is asked not to see the bicycle, but write descriptive and exploratory comments about how fast it is, its colour, the shape of its saddle, the handlebar, on the other. In other words, the researcher is simultaneously asked not to interpret the transcript but make sense of it, which is an oxymoron.

Notwithstanding, to avoid interpretation seems less and less achievable when moving ahead with the project. Each descriptive phase, except the first, is preceded by the interpretative phase of the previous case(s) when the task is specifically to render theoretical concepts to the participant's account (Smith et al., 2009, pp. 88-106).

\section{Inspired by what, exactly? - basis of conceptual comments}

In IPA's interpretative phase, the researchers are finally allowed to let their fore-conceptions come to light, and interpret the transcript at a conceptual level, against the background of their psychological knowledge, professional experiences and pre-understanding. However, the authors' comment shows a fundamental misunderstanding about the process of interpretation: 'What is important is that the interpretation was inspired by, 
and arose from, attending to the participant's words, rather than being imported from the outside' (Smith et al., 2009, p. 90).

No interpretation arises from the text itself; it is not our first-person account of our own experiences, but someone else's. We are external to the text and it does not talk to us unless we import and transpose ourselves into it. We might gain an understanding of the participant's understanding of things, yet it would be inescapably based on our external, imported fore-conceptions. Our emerging conception of the participant's understanding may differ from our initial fore-conceptions in this regard, it would necessarily arise from our own fore-understanding nonetheless, and not of the participant's. For this very reason, two IPA researchers' independent interpretation of the same transcript would hardly ever result in identical findings (Paley, 2017, Ch. 6; Brocki and Wearden, 2006; Lopez and Willis, 2004). This follows from both the concept of hermeneutic circle and the fusion of horizons.

Smith often refers to his own study (1999) on women's identity development during pregnancy to demonstrate how IPA works, and simultaneously provides an excellent example of how interpretation (and hidden prejudices) functions (Smith et al., 2009, pp. 163-175; Smith, 2007, 2004). At that time, 'prompted by the philosophical literature', Smith was interested in personal identity, and adopted his frame of reference and the interview schedule accordingly; initially with no reference to significant others as he had been 'so preoccupied with the woman's relation with herself!' (Smith, 2007). Foregrounding this framework, Smith was interviewing the women and reading their diaries with expectations in regard to this particular frame of reference. Being alert to the text alterity, Smith was, however, 'struck' by the fact that the participants often referred to their significant others during the data collection. Smith realised that his framework proved to be 'too individualistic' and, to some extent, insufficient, since the women's constant references to their significant others did not resonate and were 'not fitting with it' (Smith, 2007). In other words, the women's references did not make sense or become intelligible against the background of Smith's initial framework. This prompted Smith to consult with literature in the new area, and this is how he encountered the work of Georg Herbert Mead, who opened up a whole new world. Mead's work proved to be 'an extremely useful source' (Smith et al., 2009, p. 166): the women's references to significant others sounded as something highly intelligible in the light of Mead's concept, the relational self (Smith, 2004, 2007). Smith wonders whether when his 'old', insufficient fore-understanding occurred that was eventually replaced by a 'new', more suitable one (Smith, 2007). Gadamer argues that 'the nature of the hermeneutical experience is not that something is outside and desires admission. Rather, we are possessed by something and precisely by means of it we are opened up for the new, the different' (Gadamer, 1977, p. 9). Thus, there are, perhaps, further pressing questions regarding Smith's analysis:

1) Would Smith have ever been struck by the women's references to significant others if he had not developed a too individualistic framework and, subsequently, had not been too preoccupied with the women's relation with themselves?

2) Would the need for a 'new' concept have ever occurred in the absence of the 'old'? (Only in terms of which the 'new' proved to be new and superior.)

3) Would Smith have ever associated the references to significant others with the concept of relational self if he had not read Mead?

4) What would have Smith been struck by if he had started his analyses based on Mead's work from the outset?

and most importantly:

5) Where is bracketing in this analysis?

In evaluating how IPA is utilised in practice, Brocki and Wearden (2006) have found that interview questions were often designed on the basis of a particular theoretical framework or existing writings. Brocki and Wearden note that such enquiries, being already targeted, may impact upon the information provided by the participants. According to the authors' findings, 'it seems unlikely' that IPA researchers could initiate a project without engaging with pre-existing literature and questions relating to their topic (Brocki and Wearden, 2006). 


\section{Perspectives of interpretation}

In designing IPA, Smith et al.'s purpose was to create a method which is 'able to capture the experiential and qualitative, and which could still dialogue with mainstream psychology' (Smith et al., 2009, p. 4). How could a method whose organising principle is to bracket all theoretical fore-conceptions and professional experiences dialogue with mainstream psychology, or with any discipline whatsoever? Although illusionary, the 'naïve listener' stance of IPA, free from external or imported theoretical concepts, has been tailored only to the initial steps of the analysis (Smith et al., 2009, p. 64). Similarly to other research methods, IPA's ultimate purpose is to produce a comprehensive, generalised and conceptual interpretation of its research findings. If the sole purpose was to reveal the participants' interpretation of their experiences in their own terms, as Giorgi (2010) pointed out, the easiest way to achieve this would be to ask the participants to describe and interpret their experiences themselves. Such findings would hardly be of any scientific interest nonetheless. According to Smith, a 'good' IPA analysis provides an insightful, theory informed interpretation of its findings grounded in psychology (Smith, 2011, 2004).

There is, however, no right or wrong way of conducting IPA, researchers are urged to be innovative in the way they approach it (Smith et al, 2009, p. 80). IPA prescribes an analysis that reflects the individual view and interpretation of the researcher. Moreover, as has been argued, whatever the researchers find interesting to comment on at the very early, 'descriptive' stage of the data analysis is determined by their subjective judgement. In the absence of guidance, the conceptualisation of findings entirely depends on the choice, the qualification and the experience of the researcher, and the body of literature reviewed. Thus, the initial target of IPA, i.e. to disclose the participants unique interpretation of their experiences would necessarily result in a plethora of possible interpretation depending on the uniqueness of the researchers themselves. Both Giorgi $(2010,2011)$ and Paley (2017) have pointed out that the lack of specific guidance in terms of an objective interpretation of the research findings, a comprehensive frame of reference may put the replicability of the research and its overall scientific merit at risk.

It is notable that IPA provides for secondary, theory driven questions (Smith et al., 2009, p. 48), e.g. to what extent 'theory $y$ ' can explain the research findings. It is not clear why this requirement is optional. If the very purpose of the interpretative phase is to render a corresponding psychological concept to the emerging themes, why is it not an authoritative requirement for researchers to familiarise themselves with the relevant psychological literature that would facilitate the establishment of such connections?

\section{Why psychology?}

Notwithstanding, why would a method that claims to be hermeneutic phenomenological not take its point of departure from phenomenological philosophy at the interpretative stage from the outset? IPA is clearly committed to intersubjectivity and acknowledges that sense-making is determined by its embeddedness (Larkin et al., 2011, 2006). Smith et al. note, 'Because Dasein's experience is understood to be an in-relation-to to phenomenon, it is not really a property of the individual per se' (Smith et al., 2009, p. 29). However, the authors argue that individuals can give us a 'unique perspective' of their experiences. This approach would fall short in phenomenological terms, even though the final stage of the analysis provides for a psychological interpretation. As researchers committed to phenomenology, not only would we like to see what someone's unique understanding of certain phenomena is, but also how this understanding emerges. What is needed is precisely an inquiry into the 'in-relation-to'; i.e. what (fore-)structures are shaping that unique understanding, and what factors are shaping the structures themselves. This is the very mission of (hermeneutic) phenomenology, for the purpose of which it offers an extensive conceptual support. IPA should not ignore the assertions of the very discipline or, to use a Schutzian term, the 'stock of knowledge' (Schutz, 1972, pp. 78-83) that forms the conceptual basis of its approach. Grounding IPA's interpretative phase in phenomenological philosophy would arguably be more effective, rather than reflecting upon random psychological concepts, depending on the respective topic and the researcher's individual choice. For example, Berger and Luckmann (1967) have expanded Mead's work, and developed a comprehensive phenomenological frame of reference concerning the role of significant others in shaping identity. Notwithstanding, an introduction to phenomenology is clearly beyond the scope of this article; the works of Zahavi (2019b) and Moran (2000) provide authoritative sources for novice IPA analysts in this regard. 
Larkin et al. (2011) argue that bracketing guarantees an open-minded approach to qualitative research. Again, ignoring the theoretical framework whose very purpose is to conceptualise how we make sense of experiences while analysing how participants make sense of experiences would hardly serve that purpose; it would rather hinder the analysis (Zahavi, 2019a, 2019b, 2019c) and contradict hermeneutic tradition (Giorgi, 2010, 2011; Lopez and Willis, 2004). Zahavi notes that applying certain interviewing techniques or bracketing is not constitutive of a phenomenological method, but the employment of a comprehensive theoretical framework conceptualising the participant's 'relation to itself, to the world, and to others' (Zahavi, 2019b, p. 137). Every interpretative analysis requires an explicit and appropriate frame of reference from which the interpretation can take off (Giorgi, 2010, 2011; Lopez and Willis, 2004). Irrespective of how many times IPA researchers read and reread the transcript, how close they get to the participants' words and how attentively listen during the interview, the analysis will ultimately fail or succeed depending on how well-equipped they are in terms of theory: 'Understanding comes neither from a lot of talking, nor from busy listening around. Only one who already understands is able to listen' (Heidegger, 2010, p. 159).

\section{Conclusion}

It cannot be said that interpretation arises from the participants' account, since interpretation is always the appropriation of fore-conceptions. The participant's account gains meaning only when it becomes intelligible in terms of a particular frame of reference. In its current form, IPA leaves the interpretation to the researchers' own choice; any given IPA research is ultimately determined by the researchers' pre-existing psychological knowledge and professional experience throughout the analysis. A phenomenological focus that consistently draws from phenomenological philosophy would be instrumental for IPA's purpose. Instead of grounding the method in psychology, IPA should foreground phenomenological philosophical concepts, and interpret the transcript accordingly. This approach would not only show more consistency with hermeneutic traditions, but also make IPA a truly phenomenological analysis. This is not to say that findings could not be consulted with pre-existing psychological research informed by, or relevant to, the respective concepts of phenomenological philosophy. If IPA took the Heideggerian and Gadamerian concepts of interpretation seriously, the method would not only 'reevaluate' the application of bracketing (Smith et al.2009, p. 25), but drop it.

\section{Notes}

${ }^{1}$ Smith et al. use the 1962 translation of Being and Time.

\section{References}

Berger, P. and Luckmann, T. (1967). The Social Construction of Reality: A Treatise in the Sociology of Knowledge. London:Penguin.

Brocki, J.M. and Wearden, A.J. (2006). A critical evaluation of the use of interpretative phenomenological analysis (IPA) in health psychology. Psychology and Health, 21(1), 87-108.

Dybel, P. (2005). The Idea of Phenomenology as a Description of “Die Sachen Selbst” in Husserl and Heidegger. In A. Wiercinski (Ed.), Between Description and Interpretation: The Hermeneutic Turn in Phenomenology (pp. 247-258). Toronto: Hermeneutics Press.

Finlay, L. (2009). Debating Phenomenological Research Methods. Phenomenology \& Practice, 3(1), 6-25.

Gadamer, H. G. (2004). [1975]. Truth and Method. London: Continuum.

Gadamer, H. G. (1979). The Problem of Historical Consciousness. In P. Rabinow and W. M. Sullivan (Eds), Interpretive Social Science: A Reader (pp. 103-160). London:University of California Press.

Gadamer, H. G. (1977). Philosophical Hermeneutics. Berkeley: UCP.

Giorgi, A. (2010). Phenomenology and the Practice of Science. Existential Analysis, 21(1), 2-22.

Giorgi, A. (2011). IPA and Science: A Response to Jonathan Smith. Journal of Phenomenological Psychology, 42, 195-216.

Heidegger, M. (2010). [1953]. Being and Time. Albany: State University of New York.

Heidegger, M. (1988). The Basic Problems of Phenomenology. Bloomington: Indiana University Press.

Heidegger, M. (1985). [1979]. History of the Concept of Time. Bloomington: Indiana University Press.

Larkin, M., Eatough, V., \& Osborn, M. (2011). Interpretative phenomenological analysis and embodied, active, situated cognition. Theory \& Psychology, 21(3), 318-337. 
Larkin, M., Watts, S., \& Clifton, E. (2006). Giving voice and making sense in interpretative phenomenological analysis. Qualitative Research in Psychology, 3(2), 102-120.

Lopez, K. A., \& Willis, D. G. (2004). Descriptive Versus Interpretive Phenomenology: Their Contributions to Nursing Knowledge. Qualitative Health Research, 14(5), 726-735.

Moran, D. (2000). Introduction to Phenomenology. London: Routledge.

Paley, J. (2017). Phenomenology as Qualitative Research: A critical analysis of meaning attribution. London: Routledge.

Schutz, A. (1972). The Phenomenology of the Social World. London: Heinemann Educational Books.

Smith, J. A. (2011). Evaluating the contribution of interpretative phenomenological analysis. Health Psychology Review, 5(1), 9-27.

Smith, J. A. (2007). Hermeneutics, human sciences and health: linking theory and practice. International Journal of Qualitative Studies on Health and Well-being, 2, 3-11.

Smith, J. A. (2004). Reflecting on the development of interpretative phenomenological analysis and its contribution to qualitative research in psychology. Qualitative Research in Psychology, 1, 39-54.

Smith, J. A. (1999). Towards a relational self: Social engagement during pregnancy and psychological preparation for motherhood. British Journal of Social Psychology, 38, 409-426.

Smith, J. A., Flowers, P., \& Larkin, M. (2009). Interpretative Phenomenological Analysis: Theory, Method and Research. London: Sage.

van Manen, M. (2017). But Is It Phenomenology? Qualitative Health Research, 27(6), 775-779.

van Manen, M. (2016). Phenomenology of Practice. Abingdon: Routledge.

Wachterhauser, B. R. (1986). Introduction: History and Language in Understanding. In B. R. Wachterhauser (Ed.) Hermeneutics and Modern Philosophy (pp. 5-61). Albany: State University of New York.

Watts, M. (2011). The Philosophy of Heidegger. Durham: Acumen.

Zahavi, D. (2019a). Applied phenomenology: why is it safe to ignore the epoché. Continental Philosophy Review, https://doi.org/10.1007/s11007-019-09463-y.

Zahavi, D. (2019b). Phenomenology: The Basics. Abingdon: Routledge.

Zahavi, D. (2019c). Getting It Quite Wrong: Van Manen and Smith on Phenomenology. Qualitative Health Research, ttps://doi.org/10.1177/1049732318817547. 